\title{
Entrevista com Li Junbao
}

Márcia Schmaltz

Aprendi a exercer o ofício de tradução do chinês e português através da prática e do apoio de tradutores mais experientes. Como autodidata, comecei a colecionar livros que tratassem da formação do tradutor. Uns dos primeiros livros que adquiri foram do saudoso Paulo Rónai e, mais tarde, conheci Conversas com tradutores (BENEDETTI; SOBRAL, 2003) que se tornaram meus "companheiros" dessa atividade solitária. Sempre que possível, perguntava aos meus mestres e colegas (maioria chineses) de sua trajetória como tradutores. Os anos passaram, comecei a lecionar e deparei-me com a carência materiais para o ensino da tradução/ interpretação do chinês e português. No intuito de tornar a teoria da tradução (em sentido lato) mais interessante aos alunos, ilustrava a teoria com experiências reais narradas pelos próprios tradutores e percebi o interesse crescente dos alunos. Assim, comecei a sistematizar minha memória e iniciei o projeto de Histórias de Tradutores Chinês e Português, inspirado em "Tertúlia Tradutores" do Sesc-Pompeia de São Paulo e embasado teoricamente por D’hulst (2001) e Milton; Martins (2010). De 2010 para cá, realizaram-se seis entrevistas com tradutores profissionais das décadas de 1960 a 1990, que visa também servir de registro histórico da tradução/ interpretação entre a China e os países de expressão de língua portuguesa.

\section{Apresentação de Li Junbao}

Li Junbao nasceu em 1936, em Luoyang, província de Henan. Formado em Russo pelo Instituto Politécnico de Pequim (1953-1956) e em Português pela Universidade de Línguas Estrangeiras de Pequim (1960). Iniciou a carreira

1 http://www.tvaovivo.net/sescsp/tertulia/default_08-09.aspx, último acesso em 18/04/2013. 
no Ministério de Negócios Estrangeiros da China como intérprete em fábricas de armamentos e de comunicação nas cidades de Chongqing e Chengdu. Foi professor na Universidade Eduardo Mondlane em Maputo e na Universidade de São Paulo. Dedicou trinta anos de sua vida na seção Portuguesa da Edições em Línguas Estrangeiras da Editora do Povo da China.

Traduções: Obras escolbidas de Mao Tse-tung (s/d), Citações do Presidente Mao (1967), 37 poemas de Mao Tse-tung (1962), Casa de Chá de Lao She (s/d), Contos da dinastia Tang e Ming (s/d), Os Lusiadas: contados as crianças de João de Barros (1972), tradução com Wang Quanli; História de Portugal de A. H. Oliveria Marques (1974), Retalhos da vida de um médico de Fernando Namora (1992), História concisa de Portugal de José Hermano Saraiva (1994), Uma família inglesa de Júlio Dinis (1996), tradução com Cheng Fengwu; Dom Casmurro de Machado de Assis (2001), Dicionário Português-Chinês (2001) Chen Yongyi (ed.), Glossário cbinês-português de termos usuais (2003) em coautoria com Huang Huixian e Ahmed Youssif Eltassa, O alienista de Machado de Assis (2004), entre outros. Laureado com uma medalha de ouro pelo presidente de Portugal na década de 1990.

Esta entrevista foi realizada em sua residência em Pequim, em julho de 2011. Naquele dia de verão, ele recepcionou-me em sua biblioteca particular, repleta de obras literárias chinesas e lusófonas. $\mathrm{Na}$ sua estante encontram-se livros de Machado de Assis, Graciliano Ramos e Jorge Amado, José Saramago, entre outros.

\section{A entrevista}

Fale um pouco do contexto de sua infância durante a Segunda Guerra Mundial até a libertação da China em 1949.

Sou de Luoyan, Henan. Nasci em 1936. Naquele período, o país não estava todo em caos. Em algumas localidades havia guerra, mas em Pequim não. Por que era o centro educacional. A guerrilha ocorria principalmente em regiões fronteiriças. A partir de 1949, a maior parte dos tradutores voltou do exterior, dos EUA, da França. Jiang Jieshi [Chan Kai-chek, ex-presidente da China] disse que ele preparou a formação de jovens excelentes para o presidente Mao, pois dava grande importância à educação. As famosas universidades Qinghua e de Pequim, enviaram um grande número de alunos para estudarem no exterior e que ao concluírem os seus estudos retornaram à China, depois da Libertação (1949).

Fale um pouco do contexto de tradução em língua portuguesa na década de 1960. 
Na década de 1960 apareceu na China certo número de obras literárias do Brasil, nomeadamente, obras revolucionárias. Porque naquele tempo o entusiasmo revolucionário da China era muito alto. Tudo visava à revolução. Jorge Amado, eu acho, era um revolucionário no Brasil, a sua obra fala principalmente de descontentamento e da revolta popular, mas naquela altura, na China não havia nenhum intérprete ou tradutor da língua portuguesa. Essas obras foram traduzidas principalmente a partir do inglês. Por exemplo, Terra do sem fim [Editora do Escritor, 1958]. Outra obra que eu li quando eu estudava no Instituto de Línguas Estrangeiras [atual Universidade de Estudos Estrangeiros de Pequim], A hora próxima de Alina Paim [Editora do Povo, 1959]. Fala principalmente de [Luís Carlos] Prestes, ex-presidente do Partido Comunista do Brasil.

\section{Como começou a estudar linguas?}

Comecei por estudar a língua russa no departamento de russo na Universidade Politécnica de Pequim, em 1953, e me formei em 1956. Trabalhei como intérprete em indústrias de armamento em Chongqing e em Chengdu.

O jovem Li Junbao de 16, 20 anos o que gostava de fazer? Tinha alguma área que gostava mais, tinha alguma vocação, gostava de ler quando era pequeno? Pensava em ser intérprete, pensava em estudar russo?

Eu tinha minha própria vocação, eu gostava de estudar física, mas a necessidade do país naquela altura era outra. Tudo era organizado pelo governo de acordo com a situação interna e externa do país. A necessidade do país era a nossa vocação. Nós íamos para onde o país necessitava. E nós deveríamos ser um parafuso integrante da engrenagem. Íamos para onde o país nos designava. Por exemplo, na década de 1950 os soviéticos ajudaram muito a China: foram mais de 156 projetos em construção de grandes fábricas de tratores, rádios e radares, motores, entre outras. Eu também traduzi do russo para o chinês, manuais sobre compensador de cerâmica e segurança de peças de rádio.

\section{Como foi o início da aprendizagem português?}

No final dos anos 1960, as direções do Partido Comunista Chinês e do Partido Comunista da URSS rasgaram os acordos de cooperação assinados, e os 
peritos soviéticos foram embora. Naquela época surgiu uma palavra de ordem: "construiríamos um país com os nossos próprios esforços". E assim, fui transferido de Chongqing para Pequim. Depois fui mandando pelo Ministério dos Negócios Estrangeiros para o Instituto de Línguas Estrangeiras para estudar a língua portuguesa. Naquele tempo, nós fomos os primeiros alunos a estudar português, novembro de 1960. Éramos 15 alunos, mas com o decorrer do tempo, apenas se formaram sete. Os demais foram desclassificados.

\section{Quem eram os sete?}

Ding Xiaohang e Wang Quanli já faleceram. Xiao Sijin foi embaixador de Angola, Liu Xisun foi embaixador no Rio de Janeiro, um de sobrenome Zhu e o colega que fez o dicionário comigo, Chen Yongyi.

Havia outro curso de português oferecido pelo Instituto de Radiodifusão da China [atual Universidade de Comunicação da China]. Fazíamos parte dos quadros do MNE para estudarmos português e ganhávamos salário. Por falta de professores, estudávamos praticamente sozinhos. Aprendemos lendo o dicionário português-russo, editado pela extinta URSS. Quase não havia material de ensino.

\section{Quem eram os professores?}

Mara, uma professora brasileira, que trabalhava como locutora da rádio. Dava-nos aula uma vez por semana. Explicava muito e nós fazíamos apontamentos. Quando ela fazia-nos pergunta, nós respondíamos em russo. Mas ela não falava russo.

\section{Como vocês se comunicavam com a professora?}

Uma língua em que misturava o russo com o português. Ela não falava chinês, às vezes falávamos em inglês. Ela não era muito rigorosa. Um ano depois veio um casal de brasileiros, Ventura e Lídia. Ventura era pintor e Lídia era bailarina, ela dançava muito bem. Em 1986 quando fui ao Brasil ainda visitei o casal. Esse casal tinha uma boa impressão sobre mim, quando eu era novo.

Na década de 1960, a aprendizagem começou pelo português do Brasil, depois é que aprenderam português europeu? 
Sim. Estava relacionado à disponibilidade de professores estrangeiros. Naquele tempo havia mais professores brasileiros na China. Então aprendemos o português com uma pronúncia mais aberta e com o "erre" carregado de Jaime Martins e Angelina. Tínhamos portugueses de Angola, Moçambique e de Cabo verde (Silveira Orestes, muito bom poeta). Em Cabo Verde fala-se mais português do que outros países de expressão portuguesa, havia mais negros estudando em Portugal e o país possuía mais divisas do que outros países africanos. Diria que depois era Angola, Moçambique, São Tomé e Príncipe e, por último, Guiné-Bissau.

\section{Em que medida por saber russo ajudou-o a aprender português?}

Muito. Língua é um instrumento de comunicação e existe semelhança entre as línguas. Quando concluímos o curso de português, eu fui transferido para a Edições em Línguas Estrangeiras e traduzi as Obras Escolhidas de Mao Tse Tung com a ajuda de 3 estrangeiros. Isto foi em 1965. Um angolano, um moçambicano e um português. Trabalhávamos juntos em um mesmo escritório. O governo dava grande importância ao nosso trabalho e exigia-nos a exatidão de cada palavra de Mao.

\section{Vocês traduqiram Yulu e os poemas de Mao?}

A Citação do presidente Mao e 37 poemas de Mao. Traduzimos em um ano, trabalhávamos oito horas por dia e tínhamos que discutir palavra por palavra. Por exemplo, "o canhão explodiu. O som da bomba anunciava a retirada dos inimigos" - esse "canhão" a quem pertencia? O inimigo também poderia dar esse sinal, e assim tínhamos de fazer investigação. Nenhum dos lusófonos falava chinês e o grupo de chineses era constituído por sete ou dez tradutores. Nós traduzíamos e discutíamos entre nós [os chineses]. Depois entregávamos a tradução para eles [lusófonos], que consultavam a versão francesa e inglesa para chegarmos a algumas conclusões. Eles tinham que escolher os termos justos. Cada língua tem a sua característica para escolher o termo exato. Traduzimos cinco tomos das obras escolhidas, mas o último não foi publicado devido à intervenção do Bando dos Quatro nesse assunto, porque eles não escolheram os melhores textos de Mao Zedong [Mao Tse-tung] e quando o Bando dos Quatro foi denunciado, paramos a publicação do último tomo. Publicamos as citações do presidente em livretos avulsos.

A ideia era publicar toda a obra de Mao? 
Sim, mas alguns anos depois, abandonamos a ideia de traduzir toda a obra de Mao. Após a publicação das obras escolhidas de Mao, traduzimos a Casa de Chá, Contos da dinastia Tang e Ming para o português.

\section{É possivel pesquisarmos todas as obras traduzidas naquele periodo?}

Agora é quase impossível. Mais tarde por falta de verba, o departamento de português [Edições em Línguas Estrangeiras] foi fechado, por volta de 1990.

O senhor trabalhou dos finais de 1960 até 1990 na Edições em Linguas Estrangeiras.

Sim, mas também fui ao Brasil e Portugal. Investiguei Jorge Amado, li toda a sua obra. Li Graciliano Ramos, Vidas Secas. Machado de Assis. Trabalhei por dois anos com um professor para tirar as dúvidas. O nome do professor não me lembro mais, mas era da Associação de Escritores de São Paulo. A economia da China era de abertura, mas sem dinheiro não havia publicação. Não importa o quanto o texto seja bem escrito, mas se não tivesse efeito econômico atrativo, não era publicado pela editora. Inclusive pela Editora de Línguas Estrangeiras, que se dedica à tradução do chinês para a língua estrangeira.

\section{Dentre as obras que traduziu, qual a que mais gostou?}

De Dom Casmurro. Gostaria de ter traduzido mais, mas não houve mais o apoio da Embaixada do Brasil em Pequim. A Maria Lúcia [ex-conselheira do setor cultural da Embaixada em Pequim] disse que eu sou um grande pensador. Em Dom Casmurro não fiz a tradução fonética de "dom", preferi a tradução por sentido, para 先生 xiānshèng “senhor" em chinês. Entre Brasil e China contribui muito pouco, apenas traduzi dois livros de Machado de Assis: Dom Casmurro e O alienista. $\mathrm{Na}$ época a procura foi grande, em poucos meses se esgotaram os cinco mil exemplares. Tenho muitos amigos no Brasil. Estes livros devem ser lidos de acordo com o interesse pessoal, material e espiritual de cada pessoa. Dentre as obras técnicas, utilizamos o grande dicionário brasileiro Aurélio e o dicionário ilustrado para a edição do Dicionário Português-Chinês lançado pela Editora Comercial e reeditada por sete vezes. Ainda publiquei o Glossário chinês-português de termos usuais. Os responsáveis da Edições em Línguas Estrangeiras vieram várias vezes a minha casa para a reedição, mas não pude ajudar devido à catarata, também não pude ajudar no Dicionário Chinês-Português de Liu Huanqin. 
Para Portugal, traduzi História concisa de Portugal de José Hermano Saraiva, História de Portugal, Lusiadas de Camões e Contos para crianças de João de Barros. Ganhei uma medalha de ouro do presidente de Portugal na década de 1990.

\section{O senhor já teve experiência de dar aulas?}

Às vezes dava aula aos meus colegas. Eu era membro da Comissão de Avaliação do Currículo de Português. Também fui responsável pela certificação de tradutores de português, em que os candidatos tinham que preencher requisitos para serem promovidos [Comissão de Avaliação de Tradutores da China, 1995]. Eu fiz uma lista com quesitos para a avaliação do profissional. Também fazia revisão de tradução.

Isto servia para a promoção da carreira dentro do serviço público?

Sim. Isto é feito apenas na educação pública para a promoção de professores.

Ainda tradur?

Em relação às traduções de clássicos, ainda posso fazer.

Poderia apresentar-nos o mercado editorial da China e o papel do tradutor? O tradutor tem liberdade para sugerir obras ou fica sujeito às editoras depois da Reforma e Abertura?

Poucos anos depois da Libertação, o governo prestava muita atenção à introdução das obras revolucionárias do exterior. Por exemplo, as obras relacionadas ao marxismo e leninismo. Traduzíamos principalmente as obras de Marx, Hegel, Lenin e Stalin. Como a literatura era muito desenvolvida na URSS e durante o período revolucionário, as obras de alguns autores exerciam um importante papel na mobilização das massas. Assim traduzíamos a literatura russa. Como se tempera o aço? $?^{2}$ A nova geração lia essas obras e agia de acordo com o que dizia nessas obras, ou tomava os personagens como exemplo. É o caso de Pavel Korchagin ${ }^{2}$ é um herói excelente que influenciou uma geração inteira de chineses, até agora acho

2 Referência ao romance de Nikolai Ostrovsky (1936). O protagonista é Pavel Korchagin. 
que lembramos bem dessas estórias contadas nesses romances. Com a Reforma e Abertura econômica (1978- ) transferimos a nossa atenção ao desenvolvimento tecnológico, e cada editora passou a dar importância ao efeito econômico. Passou a se pensar se a publicação de um livro dava ou não lucro e como distribuir o prêmio a cada trabalhador [da cadeia de produção editorial] envolvido. O livro pode ser muito bom, mas se não houver interesse do público, como poderia ser pago o salário dos trabalhadores de uma editora? As editoras foram transformadas em empresas. A Editora de Línguas Estrangeiras era um empreendimento estatal, tudo era por conta do Estado e a partir da Reforma e Abertura, a empresa teve que ser autossustentável sem depender do Estado.

\section{Quando foi a sua primeira excursão ao exterior?}

Fui à Moçambique, depois à Guiné-Bissau. Trabalhei meio ano na embaixada da China em Moçambique, num grupo de investigação industrial. O português era fraco em Guiné-Bissau, e o país mais fraco ainda. O português era muito ruim, fraco, falavam crioulo. Mesmo os funcionários mais graduados. Trabalhei dois anos numa equipe médica em Guiné-Bissau, interpretava consultas médicas. Em Portugal, fiquei poucos meses. Mais tarde fui ao Brasil para a Universidade de São Paulo, convidado pela Associação de Escritores de São Paulo para pesquisar escritores como Jorge Amado, Graciliano Ramos e Machado de Assis, permaneci dois anos. O presidente do Tribunal de Contas de São Paulo me ajudou muito. Marilia Andrade, uma mulher muito rica do PT, visitou a China muitas vezes. Gostei muito da experiência no Brasil, é inesquecível. Gutemberg, editor e cientista de energia atômica, de vez em quando me convidava para jantar. Essas viagens me ajudaram muito para a atividade de tradução.

\section{Qual a sua opinião sobre as traducões chinês e português de hoje?}

Hoje existem muitas traduções péssimas das línguas chinesa e portuguesa: O livro do caminho perfeito [Daodejing]. "Quando o governo aumenta em demasiado os seus impostos a fome chega ao povo. É difícil governar o povo porque o governante só pensa nos seus próprios interesses". Essas palavras não tem valor e foram escolhidas palavras muito, muito vulgares. Faltou complementar que o governante apenas cobrava o imposto e não dava o retorno à população. Há diferenças. Visitei a editora Pensamento que me ofereceu alguns livros, inclusive o Yi Jing (I-Ching). Penso que os livros foram traduzidos do inglês. A tradução é uma arte, assim como a culinária, é preciso agradar o gosto dos leitores. 
Para o senhor, a tradução tem que ir de encontro aos leitores ou o tradutor tem que levar os leitores até a obra?

A primeira coisa é a compreensão correta do original e depois o tradutor deve com suas próprias palavras expressar e manifestar o sentido do autor. Essa compreensão não é superficial, é profunda. O tradutor de Daodejing não compreendeu a essência.

\section{Qual é o tempero certo para a tradução?}

O principal é conhecer e manejar bem a língua. Às vezes um tradutor, ele nem compreende bem o original e nem a sua língua materna e assim a tradução fica seca.

Quais são os seus procedimentos para tradução? O que costuma faz̧er?

Ler, ler e ler. Voltar a ler e é preciso pensar a fundo.

Voltando a falar de Dom Casmurro, como o senhor fezpara transpor aquele ambiente do século XIX do Brasil?

$\mathrm{Na}$ China também houve feudalismo, havia nobreza. Na minha aldeia natal havia latifundiários. Eu posso pensar no seu contexto, ligando um ao outro.

Tem visto ou acompanhado outras publicações de traducões brasileiras recentes em lingua chinesa?

Ultimamente não. Meu ponto de vista pode estar errado.

Fale um pouco da expectativa dos jovens, sobre o mercado, tendo em conta que já são 17 universidades que oferecem a licenciatura em português.

É uma desgraça quando os jovens apenas veem a língua como utilitária. É uma desgraça admitir todos os candidatos, pensando apenas no efeito econômico às universidades, não lhes importando o destino dos alunos. Uma tristeza. Há 
alguns anos, o Ministério da Educação ratificou tudo, de acordo com seu próprio interesse, uma tristeza para nós. $\mathrm{Na}$ verdade quatro anos de universidade é insuficiente para formar um tradutor, penso que sejam necessários dez anos para formar um bom tradutor, opinião também compartilhada pelo editor da Editora de Línguas Estrangeiras da China.

Atualmente cresceu muito o intercâmbio comercial entre a China e os países de expressão portuguesa. Os intérpretes que para lá vão permanecem por pouco tempo, com o objetivo de acumular economias. Já dei vários conselhos aos jovens: se quiser ganhar dinheiro vá para África, mas se for para melhorar o nível do português, não vá. Porque a língua é muito misturada e prejudica a pureza da língua que ele estudou na universidade. É bom para adquirir mais conhecimento cultural.

\section{Referências}

BENEDETTI, Ivone C.; SOBRAL, Adail. Conversas com Tradutores. São Paulo: Parábola, 2003.

D'HULST, Lieven. "Why and How to Write Translation Histories". In MILTON, John (org.) Crop, Vol. 6, número especial: Emerging Views on Translation History in Brazil, 2001, pp. 21-32. 2001.

MILTON, John; MARTINS, Marcia A. P. "Apresentação - Contribuições para Uma Historiografia da Tradução" In Tradução em Revista 1, 2010, pp. 01-10. 